\title{
Clinical Outcomes in Patients Undergoing Triple-Vessel Angioplasty for Symptomatic Coronary Artery Disease
}

\author{
Ashraf Safiya Manzil, Jithu Sam Rajan, Venkatesh Radhakrishnan \\ Department of Cardiology, Pariyaram Medical College, Pariyaram, India \\ Email: ashsmfz@yahoo.com
}

Received 25 September 2015; accepted 24 October 2015; published 27 October 2015

Copyright (C) 2015 by authors and Scientific Research Publishing Inc.

This work is licensed under the Creative Commons Attribution International License (CC BY). http://creativecommons.org/licenses/by/4.0/

cc) (i) Open Access

\begin{abstract}
Current treatment strategies for multi-vessel coronary artery disease include either coronary artery bypass surgery or percutaneous coronary intervention with stenting. The present study evaluates the morbidity and mortality among coronary artery disease patients undergoing triplevessel angioplasty. This prospective record based descriptive study was carried out in Medical College, Pariyaram, Kannur, Kerala; a tertiary care cardiac centre in South India. Fifty consecutive patients who underwent angioplasty of one or more lesions in each of the three major coronary arteries from May 2010 to July 2012 were included in the study. The study describes the clinical profile of the patients and a moderate term clinical follow-up to reassess the symptoms, functional status and left ventricular function by history, electrocardiogram, echocardiogram, and treadmill test. Mortality and morbidity were considered as end-points of the study. Event-free survival rate was $94 \%$ at a mean follow-up of 20 months. Overall $98 \%$ continued success was obtained with triple-vessel angioplasty. Triple-vessel angioplasty is a safe and effective therapy as an alternative to surgical revascularization in selected patients with triple-vessel coronary artery disease.
\end{abstract}

\section{Keywords}

Coronary Artery Disease, Revascularization, Stents, Triple-Vessel Angioplasty

\section{Introduction}

Coronary artery disease (CAD) is a major world-wide public health concern [1]. Coronary artery bypass surgery (CABG) had been the "gold standard" [2] for treatment of CAD since its inception in 1968 [3]. When percutaneous coronary intervention (PCI) was introduced in 1977 [4], the bare metal stents (BMS) were effective in 
treatment of CAD, but suffered a major drawback of higher rates of restenosis. In 2003, drug-eluting stents were introduced for the purpose of minimizing restenosis [5]. Many randomized controlled trials have documented lower rates of clinical and angiographic restenosis, target-lesion revascularization, and major adverse cardiac events (MACE) with drug-eluting stents (DES) [6]-[12]. Until recent years, PCI was meant to be pertinent only for single-vessel disease, but the advancement in device technologies instigated its use in treatment of increasingly complex disease, such as multi-vessel disease (MVD) [13].

Triple-vessel CAD, characterized by the presence of $\geq 50 \%$ stenosis in each of the three major coronary arteries i.e., the left anterior descending artery (LAD), the left circumflex artery (LCX) and the right coronary artery (RCA), is the one of the major causes of mortality in western countries. The optimal revascularization approach for patients with multi-vessel coronary disease remains a subject of debate [14]. The CABG has been considered as the conventional treatment for triple-vessel CAD [15]-[17]. In selected patients with triple-vessel disease, there is a high probability of achieving successful revascularisation of the ischemic myocardial segments by PCI [18] [19]. Due to some important intrinsic limitations including angiographic features related to the extent, location, and nature of CAD, as well as geographic, demographic and clinical factors; choice of treatment modality shifts to PCI instead of CABG [20]. Certain patients are poor surgical candidates including those with distal vessel disease, with severe systemic illness, severe left ventricular dysfunction and previous bypass surgeries. Hence, many times the triple-vessel angioplasty is performed.

Very less published data are at present available from various countries of Asia. With PCI becoming more accessible in these countries, it is being increasingly used in MVD. The outcomes in this genetically distinct population are worth studying. Thus, this study was performed to analyse the clinical outcomes following triplevessel angioplasty.

\section{Material and Methods}

\subsection{Study Design and Patient Population}

A total of fifty consecutive patients who underwent triple-vessel angioplasty in the Department of Cardiology, Medical College, Pariyaram, Kannur, Kerala from May 2010 to July 2012 were recruited for this prospective record based descriptive study. Patients with $\geq 50 \%$ stenosis in all the three major vessels (i.e., LAD, LCX, RCA) and with angiographically assessable lesions suitable for PCI were included in the study. The patients with unprotected severe left main disease, multiple chronic total occlusions (CTO) and severe diffuse disease, wherein surgery was considered to offer a more complete revascularisation at a lower risk or if they refused to give written informed consent for at least one year follow-up were excluded from the study. The study was approved by the institutional ethics committee.

A proforma which included the patient's history prior to revascularisation, the coronary risk factors, left ventricular function (LVF), and severity of the lesions and details of the procedure was made from the hospital records. These patients were then invited for a follow-up to reassess their functional status and LVF by history, electrocardiogram, echocardiogram and treadmill test. Any case of mortality was considered to be due to cardiac cause and hence a procedural failure if there was no other obvious cause like accidents. Mortality and morbidity were considered as end-points of the study.

\subsection{Statistical Analysis}

Continuous variables were presented as mean \pm standard deviation (SD) and categorical variables as counts and percentages. All data were analysed using the Statistical Package for Social Sciences (SPSS; Chicago, IL, USA) program, version 15.

\section{Results}

\subsection{Baseline, Lesion \& Procedural Characteristics}

A total of fifty patients underwent triple-vessel angioplasty, which is defined as angioplasty of at least one lesion in each of the three major coronary arteries. Out of 50 patients, there were 38 males and 12 females with a mean age of 56 years (range 34 to 76). Majority of patients had STEMI (42\%). The most common risk factor was type 2 diabetes mellitus (54\%) followed by systemic hypertension (40\%) and dyslipidemia (32\%). Normal LVF (EF > 
$60 \%$ ) was found in $70 \%$ of patients. Table 1 shows demographic characteristics of subjects.

Triple-vessel angioplasty was performed in a single sitting in 26 (52\%) cases and as a staged procedure in 24 (48\%) cases. All cases had flow limiting stenosis of the RCA and LCX. The LAD was involved in 98\% of patients. Total $84 \%$ patients underwent PTCA with stenting to all the three major vessels but the rest 8 (16\%) patients had PTCA with stenting in two vessels and POBA in one. The mean SYNTAX Score of these cases was 16.9 (range 9 to 29). The average number of lesions per patient was 3.5 (range 3 - 5) (Table 2). The percentage of lesions successfully treated by angioplasty were $93.71 \%$. The remaining lesions were in small calibre vessels $(<1.5 \mathrm{~mm})$ or not flow limiting and hence was not tackled. A drug eluting stent was put in $96.7 \%$ of instances in which a stent was used. Forty percent cases had at least one small stent (diameter $<2.5 \mathrm{~mm}$ ) and $16 \%$ had at least one long stent (length $>40 \mathrm{~mm}$ ) used. Baseline angiographic results are outlined in Table 3.

Table 1. Baseline characteristics of patients.

\begin{tabular}{|c|c|}
\hline Characteristics & Patients $=50$ \\
\hline Age (mean \pm SD, yrs) & $56 \pm 10$ \\
\hline Male, n (\%) & 38 (76\%) \\
\hline \multicolumn{2}{|l|}{ Cardiovascular risk } \\
\hline Diabetes mellitus, n (\%) & $27(54 \%)$ \\
\hline Hypertension, n (\%) & $20(40 \%)$ \\
\hline Hypercholesterolemia, n (\%) & $16(32 \%)$ \\
\hline Chronic kidney disease, n (\%) & $1(2 \%)$ \\
\hline Smoking or tobacco use, $\mathrm{n}(\%)$ & $13(26 \%)$ \\
\hline Family history of CAD, n (\%) & $12(24 \%)$ \\
\hline Previous MI, n (\%) & $21(24 \%)$ \\
\hline Cerebrovascular accident, n (\%) & $2(4 \%)$ \\
\hline Pulmonary veno-occlusive disease, $\mathrm{n}(\%)$ & $1(2 \%)$ \\
\hline \multicolumn{2}{|l|}{ Clinical presentation } \\
\hline Stable angina, $\mathrm{n}(\%)$ & $18(11.9 \%)$ \\
\hline Unstable angina, $\mathrm{n}(\%)$ & $44(29.1 \%)$ \\
\hline ST-elevated myocardial infarction, n (\%) & $21(42 \%)$ \\
\hline Non ST-elevated myocardial infarction, n (\%) & $10(20 \%)$ \\
\hline Silent ischemia, n (\%) & $1(2 \%)$ \\
\hline \multicolumn{2}{|l|}{ NYHA class } \\
\hline Class II, n (\%) & $7(14 \%)$ \\
\hline Class III, n (\%) & $15(30 \%)$ \\
\hline Class IV, n (\%) & $28(56 \%)$ \\
\hline \multicolumn{2}{|l|}{ LV systolic function } \\
\hline Normal, n (\%) & $35(70 \%)$ \\
\hline Borderline, n (\%) & $4(8 \%)$ \\
\hline Mild dysfunction, n (\%) & $6(12 \%)$ \\
\hline Moderate dysfunction, n (\%) & $5(10 \%)$ \\
\hline
\end{tabular}


Table 2. Lesion characteristics.

\begin{tabular}{lc}
\hline Characteristics & Patients $=50 /$ lesions $=175$ \\
\hline Lesion location & $49(98 \%)$ \\
Left anterior descending, n (\%) & $50(100 \%)$ \\
Right coronary artery, n (\%) & $50(100 \%)$ \\
Left circumflex, n (\%) & $1(2 \%)$ \\
Left main, n (\%) & $4(8 \%)$ \\
Ramus intermedius, n (\%) & $16.9(9-29)$ \\
Syntax score, (mean (range)) & $\mathrm{N}=152$ \\
Total No. of stents & $25.26 \pm 8.08$ \\
Average stent length, (mean \pm SD, mm) & $2.99 \pm 0.36$ \\
Average stent diameter, (mean \pm SD, mm) & \\
\hline
\end{tabular}

Table 3. Baseline angiographic results of triple-vessel angioplasty.

\begin{tabular}{cccc}
\hline No. of lesions & No. of patients & Total No. of lesions & $\begin{array}{c}\text { No. of angioplasties } \\
\text { attempted successfully }\end{array}$ \\
\hline 3 & 30 & 90 & 90 \\
4 & 15 & 60 & 53 \\
5 & 5 & 25 & $164(93.71 \%)$ \\
\hline
\end{tabular}

\subsection{Clinical Outcomes}

The average time of follow-up was 20.4 months (range 10 to 34). Forty-seven (94\%) patients had improved symptomatically or were event free. Table 4 shows clinical outcomes of the patients. Three patients (6\%) had clinical recurrence, all of whom were male. The mean age of patients with clinical recurrence was $56 \pm 8$ years and their mean SYNTAX score was $11.67 \pm 2.52$. The mean time of recurrence was 15.33 (range 6 - 27) months. One patient was expired after 27 months of procedure. One patient developed an episode of acute worsening of heart failure six months post procedure requiring hospitalisation and improved with medical management. Third patient developed recurrent angina nine months post procedure. Two patients who survived following clinical recurrence were managed medically and are at present symptom free. Thus, there was a $98 \%$ continued success with triple-vessel angioplasty in our study.

\section{Discussion}

Triple-vessel CAD is one of the classical indications for a CABG. However an increasing number of such cases are now being tackled by multi-vessel angioplasty, a tendency which is ever on the rise as cardiologists are becoming more and more experienced in technique and availabilities of facilities have improved their confidence in dealing with tough lesions.

Our study is a single centre outcome of fifty cases from South India who underwent triple-vessel angioplasty for symptomatic coronary artery disease. The mean age of patients was 56 years and male gender represented 76\% of patients. A high proportion of diabetic patients (54\%) and patients with prior MI (42\%) were present in the study. The outcome of these patients was excellent with $94 \%$ of patients remaining event free after a mean follow-up of 20 months.

There are several studies that compared the outcomes of angioplasty with CABG in triple-vessel disease. In the initial studies like ARTS and SOS, the outcome suggested CABG to be superior with significantly less need for a repeat revascularisation [17] [21]. Due to significant reduction in restenosis rates, PCI is becoming 
Table 4. Clinical outcomes after successful triple-vessel angioplasty.

\begin{tabular}{lc}
\hline Variable & $\mathrm{N}=50$ patients \\
\hline Mean follow-up (mean \pm SD, months) & $20.44 \pm 7.19$ \\
Event-free, improved, n (\%) & $47(94.0 \%)$ \\
Clinical recurrence, n (\%) & $3(6.0 \%)$ \\
Medical therapy, improved, n (\%) & $2(4.0 \%)$ \\
Death, n (\%) & $1(2.0 \%)$ \\
Continued success, n (\%) & $49(98.0 \%)$ \\
\hline
\end{tabular}

appraised as an acceptable alternative to surgery [22] [23]. Data from comparative studies like ARTS II [24] and ERACI III [25] suggest that DES-PCI was equivalent to CABG with infrequency of repeat revascularization when compared with BMS arm; however, the rate of repeat revascularization was reported to be higher when compared to CABG arm. The SYNTAX trial was one of the largest randomized trials which included more than $70 \%$ of multi-vessel CAD patients with or without left main disease done in 1800 patients to compare PCI using paclitaxel coated eluting stent with CABG [26] [27]. In the MVD subset, after 5 years of follow-up, the rate of major adverse cardiovascular and cerebrovascular events (MACCE) through 5 years was comparable in the PCI and CABG groups when the SYNTAX score was 22 or lower (33.3\% versus $26.8 \%, \mathrm{P}=0.21$ ) but were significantly high with PCI when the SYNTAX score was higher [28].

Although the five year results of the SYNTAX study suggest CABG as the preferable option in triple-vessel disease it accepts that for patients with less complex disease (low SYNTAX scores) PCI is an acceptable alternative [29]. The ACUITY Trial compared SYNTAX scores and the clinical outcomes in patients with singlevessel disease and MVD and stated that the number of diseased vessels was not a prevailing predictor, but the SYNTAX score was a powerful predictor of clinical events. For SYNTAX score $\geq 13$ in SVD and MVD, MACE at 1-year follow-up was not significantly different $(20.0 \%$ vs. $24.4 \%, \mathrm{P}=0.14)$ [30]. In present study mean SYNTAX score was 16.9, but the rate of event occurrence was only 6\%. This suggests that PCI in triple-vessel CAD is equally beneficial as CABG, in less convoluted patients having moderate SYNTAX scores.

Results of our study show that in the Asian population it is possible to achieve a good outcome following triple-vessel angioplasty with implementation of good procedural skills and technique that adds icing on cake for success of the study. A proper case selection is imperative so that more complex cases should have a less threshold for CABG.

\section{Conclusion}

It appears that triple-vessel angioplasty is a safe and effective therapy that may represent a reasonable alternative to surgical revascularization in selected patients with triple-vessel CAD where procedural technique and skill play a crucial role. However, further studies are necessitated in the Asian population before a consensus is formulated.

\section{References}

[1] Mozaffarian, D., Benjamin, E.J., Go, A.S., Arnett, D.K., Blaha, M.J., Cushman, M., et al. (2015) Heart Disease and Stroke Statistics-2015 Update: A Report from the American Heart Association. Circulation, 131, e29. http://dx.doi.org/10.1161/CIR.0000000000000152

[2] Casey, C. (2004) Multi-Vessel Coronary Disease and Percutaneous Coronary Intervention. Heart, 90, 341-346. http://dx.doi.org/10.1136/hrt.2003.018986

[3] Favaloro, R.G. (1968) Saphenous Vein Autograft Replacement of Severe Segmental Coronary Artery Occlusion: Operative Technique. The Annals of Thoracic Surgery, 5, 334-339. http://dx.doi.org/10.1016/S0003-4975(10)66351-5

[4] Grüntzig, A.R., Senning, Å. and Siegenthaler, W.E. (1979) Nonoperative Dilatation of Coronary-Artery Stenosis: Percutaneous Transluminal Coronary Angioplasty. New England Journal of Medicine, 301, 61-68. http://dx.doi.org/10.1056/NEJM197907123010201

[5] Hannan, E.L., Wu, C., Walford, G., Culliford, A.T., Gold, J.P., Smith, C.R., et al. (2008) Drug-Eluting Stents vs. Co- 
ronary-Artery Bypass Grafting in Multivessel Coronary Disease. New England Journal of Medicine, 358, 331-341. http://dx.doi.org/10.1056/NEJMoa071804

[6] Indolfi, C., Pavia, M. and Angelillo, I.F. (2005) Drug-Eluting Stents versus Bare Metal Stents in Percutaneous Coronary Interventions (a Meta-Analysis). The American Journal of Cardiology, 95, 1146-1152. http://dx.doi.org/10.1016/j.amjcard.2005.01.040

[7] Moses, J.W., Leon, M.B., Popma, J.J., Fitzgerald, P.J., Holmes, D.R., O’Shaughnessy, C., et al. (2003) SirolimusEluting Stents versus Standard Stents in Patients with Stenosis in a Native Coronary Artery. New England Journal of Medicine, 349, 1315-1323. http://dx.doi.org/10.1056/NEJMoa035071

[8] Holmes, D.R., Leon, M.B., Moses, J.W., Popma, J.J., Cutlip, D., Fitzgerald, P.J., et al. (2004) Analysis of 1-Year Clinical Outcomes in the SIRIUS Trial a Randomized Trial of a Sirolimus-Eluting Stent versus a Standard Stent in Patients at High Risk for Coronary Restenosis. Circulation, 109, 634-640. http://dx.doi.org/10.1161/01.CIR.0000112572.57794.22

[9] Ardissino, D., Cavallini, C., Bramucci, E., Indolfi, C., Marzocchi, A., Manari, A., et al. (2004) Sirolimus-Eluting vs Uncoated Stents for Prevention of Restenosis in Small Coronary Arteries: A Randomized Trial. JAMA, 292, 27272734. http://dx.doi.org/10.1001/jama.292.22.2727

[10] Katritsis, D.G., Karvouni, E. and Ioannidis, J.P. (2005) Meta-Analysis Comparing Drug-Eluting Stents with Bare Metal Stents. The American Journal of Cardiology, 95, 640-643. http://dx.doi.org/10.1016/j.amjcard.2004.10.041

[11] Regar, E., Serruys, P., Bode, C., Holubarsch, C., Guermonprez, J., Wijns, W., et al. (2002) Angiographic Findings of the Multicenter Randomized Study with the Sirolimus-Eluting Bx Velocity Balloon-Expandable Stent (RAVEL) Sirolimus-Eluting Stents Inhibit Restenosis Irrespective of the Vessel Size. Circulation, 106, 1949-1956. http://dx.doi.org/10.1161/01.CIR.0000034045.36219.12

[12] Morice, M.-C., Serruys, P.W., Sousa, J.E., Fajadet, J., Ban Hayashi, E., Perin, M., et al. (2002) A Randomized Comparison of a Sirolimus-Eluting Stent with a Standard Stent for Coronary Revascularization. New England Journal of Medicine, 346, 1773-1780. http://dx.doi.org/10.1056/NEJMoa012843

[13] Mohr, F.W., Morice, M.-C., Kappetein, A.P., Feldman, T.E., Ståhle, E., Colombo, A., et al. (2013) Coronary Artery Bypass Graft Surgery versus Percutaneous Coronary Intervention in Patients with Three-Vessel Disease and Left Main Coronary Disease: 5-Year Follow-Up of the Randomised, Clinical SYNTAX Trial. The Lancet, 381, 629-638. http://dx.doi.org/10.1016/S0140-6736(13)60141-5

[14] Panchal, K., Patel, S. and Bhatt, P. (2012) Drug-Eluting Stents in Multivessel Coronary Artery Disease: Cost Effectiveness and Clinical Outcomes. Advances in Pharmacological Sciences, 2012, Article ID: 679013. http://dx.doi.org/10.1155/2012/679013

[15] Hoffman, S.N., TenBrook, J.A., Wolf, M.P., Pauker, S.G., Salem, D.N. and Wong, J.B. (2003) A Meta-Analysis of Randomized Controlled Trials Comparing Coronary Artery Bypass Graft with Percutaneous Transluminal Coronary Angioplasty: One- to Eight-Year Outcomes. Journal of the American College of Cardiology, 41, 1293-1304. http://dx.doi.org/10.1016/S0735-1097(03)00157-8

[16] Buszman, P.E., Buszman, P.P., Bochenek, A., Gierlotka, M., Gąsior, M., Milewski, K., et al. (2014) Comparison of Stenting and Surgical Revascularization Strategy in Non-ST Elevation Acute Coronary Syndromes and Complex Coronary Artery Disease (From the Milestone Registry). The American Journal of Cardiology, 114, 979-987. http://dx.doi.org/10.1016/j.amjcard.2014.07.008

[17] van den Brand, M.J., Rensing, B.J., Marie-Angèle, M.M., Foley, D.P., de Valk, V., Breeman, A., et al. (2002) The Effect of Completeness of Revascularization on Event-Free Survival at One Year in the ARTS Trial. Journal of the American College of Cardiology, 39, 559-564. http://dx.doi.org/10.1016/S0735-1097(01)01785-5

[18] Moustapha, A. and Anderson, H.V. (2000) Revascularization Interventions for Ischemic Heart Disease. Current Opinion in Cardiology, 15, 463-471. http://dx.doi.org/10.1097/00001573-200011000-00012

[19] Morrison, D. (2005) Multivessel Percutaneous Coronary Intervention: A New Paradigm for a New Century. Minerva Cardioangiologica, 53, 361-377.

[20] Kim, L.J., King, S.B., Kent, K., Brooks, M.M., Kip, K.E., Abbott, J.D., et al. (2009) Factors Related to the Selection of Surgical versus Percutaneous Revascularization in Diabetic Patients with Multivessel Coronary Artery Disease in the BARI 2D (Bypass Angioplasty Revascularization Investigation in Type 2 Diabetes) Trial. JACC: Cardiovascular Interventions, 2, 384-392. http://dx.doi.org/10.1016/j.jcin.2009.01.009

[21] Booth, J., Clayton, T., Pepper, J., Nugara, F., Flather, M., Sigwart, U., et al. (2008) Randomized, Controlled Trial of Coronary Artery Bypass Surgery versus Percutaneous Coronary Intervention in Patients with Multivessel Coronary Artery Disease Six-Year Follow-Up from the Stent or Surgery Trial (SoS). Circulation, 118, 381-388. http://dx.doi.org/10.1161/CIRCULATIONAHA.107.739144

[22] Kirtane, A.J., Gupta, A., Iyengar, S., Moses, J.W., Leon, M.B., Applegate, R., et al. (2009) Safety and Efficacy of 
Drug-Eluting and Bare Metal Stents Comprehensive Meta-Analysis of Randomized Trials and Observational Studies. Circulation, 119, 3198-3206. http://dx.doi.org/10.1161/CIRCULATIONAHA.108.826479

[23] Athappan, G., Patvardhan, E., Tuzcu, M.E., Ellis, S., Whitlow, P. and Kapadia, S.R. (2013) Left Main Coronary Artery Stenosis: A Meta-Analysis of Drug-Eluting Stents versus Coronary Artery Bypass Grafting. JACC: Cardiovascular Interventions, 6, 1219-1230. http://dx.doi.org/10.1016/j.jcin.2013.07.008

[24] Daemen, J., Kuck, K.H., Macaya, C., Le Grand, V., Vrolix, M., Carrie, D., et al. (2008) Multivessel Coronary Revascularization in Patients with and without Diabetes Mellitus: 3-Year Follow-Up of the ARTS-II (Arterial Revascularization Therapies Study-Part II) Trial. Journal of the American College of Cardiology, 52, 1957-1967. http://dx.doi.org/10.1016/j.jacc.2008.09.010

[25] Rodriguez, A.E., Grinfeld, L., Fernandez-Pereira, C., Mieres, J., Rodriguez, A.M., Berrocal, D., et al. (2006) Revascularization Strategies of Coronary Multiple Vessel Disease in the Drug Eluting Stent Era: One Year Follow-Up Results of the ERACI III Trial. Euro Intervention: Journal of Euro PCR in Collaboration with the Working Group on Interventional Cardiology of the European Society of Cardiology, 2, 53-60.

[26] Ong, A.T., Serruys, P.W., Mohr, F.W., Morice, M.-C., Kappetein, A.P., Holmes, D.R., et al. (2006) The SYNergy between Percutaneous Coronary Intervention with TAXus and Cardiac Surgery (SYNTAX) Study: Design, Rationale, and Run-In Phase. American Heart Journal, 151, 1194-1204. http://dx.doi.org/10.1016/j.ahj.2005.07.017

[27] Serruys, P.W., Morice, M.-C., Kappetein, A.P., Colombo, A., Holmes, D.R., Mack, M.J., et al. (2009) Percutaneous Coronary Intervention versus Coronary-Artery Bypass Grafting for Severe Coronary Artery Disease. New England Journal of Medicine, 360, 961-972. http://dx.doi.org/10.1056/NEJMoa0804626

[28] Morice, M.-C., Serruys, P.W., Kappetein, A.P., Feldman, T.E., Ståhle, E., Colombo, A., et al. (2014) Five-Year Outcomes in Patients with Left Main Disease Treated with Either Percutaneous Coronary Intervention or Coronary Artery Bypass Grafting in the Synergy between Percutaneous Coronary Intervention with Taxus and Cardiac Surgery Trial. Circulation, 129, 2388-2394. http://dx.doi.org/10.1161/CIRCULATIONAHA.113.006689

[29] Kappetein, A.P., Head, S.J., Morice, M.-C., Banning, A.P., Serruys, P.W., Mohr, F.-W., et al. (2013) Treatment of Complex Coronary Artery Disease in Patients with Diabetes: 5-Year Results Comparing Outcomes of Bypass Surgery and Percutaneous Coronary Intervention in the SYNTAX Trial. European Journal of Cardio-Thoracic Surgery, 43, 1006-1013. http://dx.doi.org/10.1093/ejcts/ezt017

[30] Caixeta, A., Généreux, P., Palmerini, T., Lansky, A.J., Mehran, R., Dangas, G.D., et al. (2014) Prognostic Utility of the SYNTAX Score in Patients with Single versus Multivessel Disease Undergoing Percutaneous Coronary Intervention (From the Acute Catheterization and Urgent Intervention Triage StrategY [ACUITY] Trial). The American Journal of Cardiology, 113, 203-210. http://dx.doi.org/10.1016/j.amjcard.2013.08.035 